\title{
PART II. REVIEWS AND BIBLIOGRAPHICAL NOTICES.
}

The Carrier Problem in Infectious Diseases. By J. C. G. Ledingham, M.B., D.Sc., Chief Bacteriologist, Lister Institute of Preventive Medicine, London; and J. A. Arkwright, M.D., Assistant-Bacteriologist, Lister Institute of Preventive Medicine, London. London : Edward Arnold; New York: Longmans, Green \& Co. 1912. Pp. vii +319 .

THIS is a most valuable addition to the series of International Medical Monographs which, under the able editorship of Leonard Hill and William Bulloch, are being issued on subjects of immediate medical interest. As is pointed out in the preface to this and companion volumes, the object of the series is to present from the pen of first hand authorities the present knowledge of their own subjects in a duly balanced, concise and accurate form. The subject of the present volume is essentially one on which a standard volume summarising critically the knowledge that has been gained to date is urgently required, and as far as we can judge the authors have done their work most excellently. The largest section in the book deals with the carrier problem in enteric fever; exhaustive chapters on the same problem in paratyphoid fever, in diphtheria, in epidemic cerebrospinal meningitis, in dysentery and in cholera, complete the work. We are glad to notice that as regards typhoid fever due credit is given to Horton-Smith for his early perspicacity in recognising the possible importance of typhoid carriers. The entire problem is discussed at length in all its bearings, and all literature of value in this connection is dealt with in its proper place. The facts detailed are beyond the criticism of a mere reviewer, who may, however, admire 
the way in which the complex and varied details of the problem have been grouped together by the writers. So far but little advance in curing typhoid carriers can be chronicled, but the success attending the administration of Borovertin (a compound of urotropin and boric acid) in the case of urinary carriers is noteworthy.

The chapters on diphtheria and cerebrospinal meningitis are full of interest. In neither of these diseases is the chronic carrier met with in the same sense as in typhoid fever, but the problem of how to deal with persons who harbour the characteristic organism of these infections for two to three months after original infection is, nevertheless, a pressing one. Perhaps the most striking advance in connection with the more recent epidemic of cerebrospinal meningitis was the recognition of the pharyngeal mucosa as the primary habitat of the meningococcus. The proof of this and the discovery of the organism in apparently normal individuals is fully dealt with. Of less interest in this country are the chapters on dysentery and cholera, though in the facts detailed concerning the former disease we may find explanations of some anomalous symptoms met with at home in patients who have previously lived in countries where dysentery was prevalent.

We have much pleasure in cordially recommending this work as a scientific and up-to-date presentation of the carrier problem in disease.

Vaccine Therapy: Its Theory and Practice. By R. W. ALlen, M.D., B.S. (Lond.); Late Clinical Pathologist to the Mount Vernon Hospital for Disease. Fourth Edition. London: H. K. Lewis. 1912. Pp. $\mathrm{x}+444$. THIs book has now reached a fourth edition, and has long since justified its existence. We are sure it will be eagerly purchased, and we hope it will be widely read, for in days when the hypodermic syringe laden with a dose of more or less appropriate vaccine is in the hands of every practitioner it is advisable that some reference book on the 
subject of vaccine therapy should be available, and that reliance should not be placed, for information merely, on the catalogues of medical firms. One of the lessons that this book urges is the necessity of ascertaining the true bacterial cause of any given disease, at any rate as nearly as possible, before pursuing it with a vaccine. Such a lesson is, of course, obvious, but it is one that is very often neglected, and now that vaccines for all sorts and conditions of disease are readily obtainable on the market, and are known to do little harm even if their beneficial results are not apparent, there is a grave danger not only to vaccine therapy itself, but also to scientific treatment in general from the indiscriminate and ill-judged employment of such agencies. It is now no unusual thing to meet with medical men who enthusiastically inform one that some trivial ailment has rapidly recovered after the use of some vaccine - an ailment which in nine cases out of ten would recover in just as short a time without any treatment whatsoever, or with some simpler, but no doubt more old-fashioned, treatment. The explanation of the way in which vaccines produce their effect has, moreover, impressed the public mind, much in the same way that Bulgarian milk did a few years ago, and in many cases vaccine treatment is demanded for conditions that obviously do not require it. In this way we believe that a schocl of qualified quackery is growing up, and we take this opportunity of raising our protest. We do not wish to be misunderstood. Vaccine therapy is most useful, and all honour to Sir Almroth Wright, its introducer ; but it must not be run as a cureall which cannot fail, no matter what the disease against which the vaccine is employed.

To return now to the volume before us. It is in our opinion written in a most temperate and scientific spirit. The writer is undoubtedly enthusiastic, but still speaks with caution, and presents honestly the results of his own experience. Practically the whole field of vaccine therapy is covered, and both as a reference book in which the facts relating to the experience of vaccine treatment in any 
given disease can be readily found, and as a volume for immediate perusal for the sake of gaining an up-to-date knowledge of vaccine therapy in all its branches, we cordially recommend it.

Studies in Clinical Medicine. By C. O. Hawthorne,

M.D. London : John Bale, Sons \& Danielsson, Ltd. 1912. Pp. viii +441 .

THIs little volume consists of a collection of papers and essays for the most part previously published in the various medical journals, and the author has earned our gratitude by placing a quantity of diverse information in such a convenient and compact form.

Though the range of subjects treated is fairly wide, comprising descriptions of special features of diseases affecting practically all the body "systems," two of these subjects receive special attention in a number of essays, and we think deservedly. One of these is rheumatism, particularly in its relation to rheumatoid arthritis. It is pointed out that most authorities regard the occurrence of subcutaneous fibrous nodules as infallible evidence of "rheumatism" in the strict, if somewhat indefinite, sense of the word. The writer brings forward evidence and cases to show that these nodules undoubtedly occur in cases of rheumatoid arthritis, the obvious inference being either that this disease is very closely allied to rheumatism or that the general view with regard to the nodules is mistaken. Unfortunately, "it is not the ambition of this essay to suggest which alternative should be selected."

The other topic which receives considerable space is the ophthalmoscopic findings in various general diseases. It is to be feared that many physicians give this aspect of diagnosis less attention than the results would warrant not, of course, through ignorance of its importance, but probably because they have not themselves practised the use of the instrument, and examination by a "specialist" involves inconvenient delay or expense. A perusal of some of these essays leaves one with a firm determination 
to correct the omission, and to carry the ophthalmoscope in the other pocket.

The most readable part of the book, however, is undoubtedly the dozen or so of clinical lectures given towards the end. These are, in our opinion, as good as any we remember reading, and better than most. They are eminently clear, logical and scientific, but read with the ease and interest of a novel.

The book is scarcely one for reference, though a good index is provided; but for spare moments at the study fire we can cordially recommend it as most profitable and entertaining.

Achondroplasia : Its Nature and its Cause. By Dr. Murk JANSEN, Lecturer on Orthopædic Surgery, University of Leiden. Leiden : E. J. Brill, Ltd. ; London : Baillière, Tindall \& Cox. 1912. Demy Quarto. Pp. $\mathrm{vi}+98$.

DocTOR JANSEN has given us a most interesting monograph upon an intensely interesting subject. Yet we feel that probably but few of his readers will accept his main contention that an abnormal amniotic pressure affords the explanation for all the main features to be observed in typical cases of achondroplasia. Put as shortly as possible, he believes that abnormal pressure within the amniotic sac of the developing embryo leads to a diminished blood supply of the cartilages at a time when these latter are increasing in volume more rapidly than the other tissues of the embryo. In this way the growth of the cartilaginous skeleton is stunted, and the later formed cartilages, as for instance those of the limbs, are most affected. In a most interesting manner Dr. Jansen seeks to explain each of the peculiarities of the typical achondroplastic, and to show that each may have its origin from such an increased amniotic pressure as he postulates. At the same time he freely admits that the non-characteristic symptoms cannot with certainty be included among the consequences direct or indirect of such pressure, and the probable 
influence of diminished pituitary secretion is clearly indicated.

The observed facts upon which Dr. Jansen bases his hypothesis are set out most lucidly, and at all times the argument can be most easily followed, yet we feel that the condition is too complex for so mechanical an explanation.

In spite of his warm advocacy we are not convinced that " the achondroplastic is an amnion dwarf, folded up by a dwarf amnion, by the enhanced hydrostatic pressure of which it has been disturbed in the development of its skeleton," and that " the wonders . . . of achondroplasia may be easily understood and arranged in chronological order, if we accept the principle that amnion pressure is able to disturb the nutrition and growth of part of the embryo, whilst the non-affected parts continue their growth."

The monograph is attractively brought out, well printed, and fully illustrated.

A Text-book on the Practice of Gyncecology for Practitioners and Students. By William Easterly Ashton, M.D., LL.D., Fellow of the American Gynæcological Society ; formerly Lecturer on Gynæcology in the Jefferson Medical College, Philadelphia; one of the Founders of the Congrès International de Gynécologie et d'Obstetrique, \&c. With 1,050 New Line Drawings illustrating the Text by John V. Alteneder. Fifth Edition, thoroughly revised. Philadelphia and London: W. B. Saunders Company. 1912. Royal 8vo. Pp. 1,100.

THIs work is noted for the amount of information it concerns-indeed in this respect it is encyclopædic, and also in the number of its illustrations, which, though somewhat diagrammatic, are none the less valuable. The fifth edition has been thoroughly revised, both in the ætiology, pathology, and treatment of different gynæcological diseases, and in the description of new operations. The chapter on the blood in relation to surgery has been 
considerably changed, and made to conform with recent advances in hæmatology. The chapter on the $x$-rays has been enlarged, and their use in the treatment of fibroid tumours has been discussed, as also in cases of obstinate metrorrhagia and menorrhagia. The palliative treatment of cancer of the uterus and vagina receives additional attention. Recent advances in the diagnosis and treatment of syphilis have been carefully considered.

A curious Americanism is to be noted in places. Thus, a glass irrigating jar with a rubber tube ending in a catheter is described as "Ashton's apparatus for hydrostatic dilatation of the bladder," and further on the same apparatus with a class nozzle instead of a catheter is described as "Ashton's general irrigation apparatus." It seems a simple way of becoming an inventor.

A Clinical Manual of the Malformations and Congenital Diseases of the Foetus. By Professor Dr. R. BIrNBAUM, Chief Physician to the University Clinic for Women at Göttingen. Translated and Annotated by G. Blacker, M.D., B.S., F.R.C.P., F.R.C.S., Obstetric Physician to University College Hospital, and the Great Northern Central Hospital ; Teacher of Practical Midwifery at University College Hospital Medical School, \&c. With 58 Illustrations in the Text, and eight Plates. London : J. \& A. Churchill. 1912. Royal 8vo. Pp. xiv +379 .

ThIs work is perhaps the first, or one of the first, of its scope to appear in English, and it is was this fact that mainly lead Dr. Blacker to translate it. The author endeavours to treat his subject from the anatomical, pathological, physiological, and clinical standpoints, and succeeds in producing a most valuable work of reference.

Amongst the headings of the different chapters are found the following :--Arrest of development of the whole embryonic rudiment; defective formation of the skullcap ; hydrocephalus ; malformations of the face ; malformations of the neck; umbilical hernia ; malformations of 
the genital organs; double malformations; the legal rights of monsters.

The book deals as clearly as is possible at the present time with a most difficult subject, and constitutes a valuable work of reference.

Obstetrics. A Text-book for the use of Students and Practitioners. By J. Whitridge Williams, Professor of Obstetrics, Johns Hopkins University ; Obstetricianin-Chief to the Johns Hopkins Hospital; Gynæcologist to the Union Protestant Infirmary, Baltimore, M.D. Third, enlarged and revised, Edition. With Sixteen Plates and Sixty-eight Illustrations in the Text. New York and London: D. Appleton \& Co. 1912. Royal 8vo. Pp. $\mathrm{xxx}+997$.

OBSTETRICIANS generally will extend a very warm welcome to the new edition of Professor Whitridge Williams' work on Obstetrics. The book has been very carefully revised throughout, and in some places important changes have been made. These changes are particularly to be found in the chapters on development of the ovum, the organic changes incident to pregnancy, pubiotomy, Cæsarean section, pernicious vomiting, and the treatment of contracted pelvis. The bibliographical references at the end of each chapter have also been brought up to date.

Professor Williams' views on the ætiology of pernicious vomiting have always been received with attention, though they may not always be accepted. He emphasises them with great clearness in the present edition, and ends by stating that there is abundant evidence to prove that certain cases of pernicious vomiting are due to a toxæmia, which is associated with a high ammonia coefficient, a marked reduction in the output of urea, and profound degenerative lesions in the liver and kidney. He further considers that the liver lesions are in the nature of a degeneration or necrosis effecting the central portions of the lobules, whilst in eclampsia the process is essentially one of thrombosis starting in the peri-portal spaces; and 
he states that he considers the two diseases have only two points in common, namely, that both occur in pregnant women and that both are manifestations of disturbed metabolism.

Professor Williams is equally interesting and instructive when he comes to discuss the rtiology of eclampsia, but his treatment is disappointing. So far the lowest mortality rates in a considerable series of cases have been obtained by Professor Stroganoff and at the Rotunda Hospital. Professor Williams' criticism of Stroganoff's treatment is that with one exception no one seems to have taken it seriously, and he does not even mention the treatment originated by Dr. Tweedy at the Rotunda Hospital. At the same time he places the mortality of eclampsia at between 20 and 25 per cent., and this is very considerably above the mortality amongst the cases treated by Stroganoff or at the Rotunda Hospital.

We cannot speak too highly of Professor Williams' work, which is in all ways a model of what a modern work on midwifery should be.

Hoblyn's Dictionary of Terms used in Medicine and the Collateral Sciences. Fifteenth Edition. Revised throughout, with numerous additions. By JoHN A. P.

- Price, B.A., M.D. Oxon., M.B. Lond., Surgeon to the Royal Berks Hospital ; late Physician to the Royal Hospital for Children and Women. London : G. Bell \& Sons, Ltd. 1912. Cr. 8vo. Pp. $\mathrm{x}+878$.

IT is our pleasant duty to draw attention to the recent publication of the fifteenth edition of this deservedly popular Medical Dictionary. The Editor has paid us the compliment of making some corrections which we suggested when reviewing the fourteenth edition in a friendly spirit some three years ago-in March, 1910.

The scientific standing of the work has been very much raised since Dr. Price took in hand the revision of its pages. He has paid special attention to terms used in bacteriology, and in a brief preface acknowledges his indebtedness in 
this department to Muir and Ritchie's classical work on the subject. "Anaphylaxis" is defined in the very words of these authors.

Why does Dr. Price still countenance such mis-spellings as "Anchylosis" and "Anchylostoma," which, as he actually points out, are wrong. Under the former, he writes: "This term should be spelled ankylosis: the Greek letter is $\kappa$ not $\chi . "$

Under "Angina" he correctly states that " the ' $i$ ' is short," but in referring to the root ang or anc, he omits any mention of the Greek words $\dot{a} \gamma \chi \omega$, to press tight, strangle, throttle, and à $\chi^{o}{ }^{\prime} \nu \eta$, a throttling or strangling. This latter word with its short omicron should settle the question of angina.

RECENT WORKS ON DISEASES OF CHILDREN.

1. The Medical Diseases of Children. By. T. R. C. WHIPHaM, M.A., M.D. (Oxon), M.R.C.P. ; Physician to Evelina Hospital for Sick Children. London : University Press (Hodder \& Stoughton \& Henry Frowde). 1912. Demy 8vo. Pp. xi +417.

2. The Nutrition of the Infant. By RaLPH VINCENT, M.D. Fourth Edition. London: Baillière, Tindall \& Cox. 1913. Demy 8vo. Pp. xviii +343 .

1. The chief defect in Dr. Whipham's work is its great resemblance to many other books on the same subject. The general form of the book leaves nothing to be desired. It is readable, concise, well illustrated, and includes practically all the pathological conditions of a non-surgical nature that the student or general practitioner is likely to come across. But one looks in vain for any new theory or even new form of treatment to justify its existence, or at any rate to raise it above the level of so many similar works.

If pædiatrics is to advance in this country, it is time that men of such wide experience, and with such opportunities for observation and research as the authors of 
these small text-books shall confine themselves to monographs on special diseases, of which they have made special study. These would then afford valuable material for the larger text-books.

2. Is the fourth edition of this valuable work--which is the best exposition of the " percentage method " published in England-Dr. Vincent still carries on sturdily his crusade against all pasteurisation and sterilisation of milk. His description of the methods of cooling and preparing the milk for the Infants' Hospital were always interesting, but the present edition of his book has been rendered much more valuable by the addition of an excellent chapter on the bacteriology of milk. This chapter is the result of wide original research on the part of the author, and whether one agrees with his conclusions or not, may be read with profit practically as a monograph on this subject. Its value is also enhanced by a series of most excellent micro-photographs. A great deal of new work has been added to the chapters on intestinal disorders, and lastly, a valuable addition to the book from the practical point of view is the description of the "fat whey" method, which has proved successful in cases treated at home where "percentage" milk was not obtainable.

A Text-book of Obstetrics. By Barton Cooke Hinst, M.D., Professor of Obstetrics in the University of. Pennsylvania; Gynæcologist to the Huward, the Orthopædic, and the Philadelphia Hospitals, \&c. Seventh Edition, revised and enlarged. With 895 Illustrations, 53 of them in Colours. Philadelphia and London: W. B. Saunders Company. 1912. 8vo. Pp. 1013.

Dr. Barton Hirst's well-known work on Midwifery has reached a seventh edition. In it the book has been thoroughly revised and rearranged, the order of the chapters now being-as the author admits-much more 
logical. In the previous edition a description of the common gynæcological operations was introduced, and this innovation has been continued. In addition there is an extension of the article on Diseases of the Breast.

Dr. Hirst's work is so generally known that it does not call for an extended review, and we need only say that the present edition fully maintains the high reputation of its predecessors.

Pye's Surgical Handicraft. A Manual of Surgical Manipulations, Minor Surgery, and other Matters connected with the Work of House Surgeons and Surgical Dressers. Edited and largely rewritten by W. H. Clayton-Greene, B.A., M.B., B.C. (Cantab.), F.R.C.S. (Eng.); Surgeon to St. Mary's Hospital; Lecturer on Surgery in the Medical School, \&c. Sixth Edition. Bristol : John Wright \& Sons. 1912. Demy 8vo. Pp. xvi +595 .

THIs book is all that it professes to be, it is in fact a very full treatise on all ordinary surgical treatment apart from actual operation. The matter is arranged in an orderly manner, making it easy to look up any particular subject with rapidity. The directions given are all sound and the language used is clear. All through the book will be found useful practical hints. The chapters on "The Arrest of Hæmorrhage" and "Emergencies, Surgical and General" will well repay careful reading. In short, we can thoroughly recommend the book to all students and qualified men who wish to learn surgical handicraft.

A Text-book of Gyncecology. By William S. Gardner, M.D.; Professor of Gynæcology in Baltimore. New York and London: Appleton \& Co. 1912. Demy 8vo. Pp. 286. With 138 Illustrations.

THIs is a short, clearly written book for students only. It contains the essential facts relating to common gynæ. 
cological conditions, and rare conditions are touched on very lightly. Its teaching, so far as it goes, appears to us to represent correctly modern views, and the majority of the illustrations, though they are not artistic, show what they are intended to show. There are a number of what the author calls " photomicrographs," but as they are not very clear their value is not very evident. On the whole, we are rather inclined to regard the work as somewhat in the nature of a "cram-book."

London Medical Publications. The Diseases of the Skin. By Willmott Evans, M.D., F.R.C.S.; Senior Surgeon to the Hospital for Diseases of the Skin, Blackfriars. With Thirty-two Illustrations. London : University of London Press. 1912. Pp. xiv +375.

ThE writer states in his Preface to this book that the reason so many students and practitioners fail to obtain a satisfactory knowledge of dermatology is that the many excellent standard treatises on the subject are too advanced for those who are entering on the study. In consequence the descriptions in this book have been written in as simple a style as is compatible with correctness. From this abstract from the Preface it is possible to understand the type of book that may be expected, and we may say at once both that we are in agreement with the writer's views concerning the difficulty of the subject as viewed by the student in the average text-book and that in our opinion he has admirably fulfilled his object in writing an easy and non-repellent work on skin diseases. We only regret that the work could not have been illustrated by coloured plates throughout, as non-coloured illustrations convey a very poor idea of skin affections, more especially to a student who has seen very few skin cases.

No special comment is required on the text. It is, as already stated, clear and succinct, and above all unburdened with a multitude of unnecessary names. A sufficient number of good every-day prescriptions are included. The print-an important point-is of rather large type, and 
thereby still further removes the impression of difficulty so frequently produced by the pages of the learned but wearisome pages of more ambitious works.

\section{WORKS ON BIOCHEMISTRY.}

1. The Simple Carbohydrates and the Glucosides. By E. Frankmand Armstrong, D.Sc., Ph.D. Second Edition. London : Longmans, Green \& Co. 1912. Royal 8vo. Pp. viii +17 !.

2. The Physiology of Protein Metabolism. By E. P. CathCaRT, M.D., D.Sc. London : Longmans, Green \& Co. 1912. Royal 8vo. Pp. viii+142.

3. The Protein Element in Nutrition. By MaJor $\mathrm{D}$. M'CAY, M.B., B.C.h., B.A.O., M.R.C.P., I.M.S. London: Edward Arnold. 1912. Demy 8vo. Pp. xv.+216.

4. Oxidations and Reductions in the Animal Body. By H. D. DAKIN, D.Sc., F.I.C. London : Longmans, Green \& Co. 1912. Royal 8vo. Pp. viii +135 .

5. Lead Poisoning and Lead Absorption. By Thомаs M. LEGGe, M.D., and Kenneth W. Goadby, M.R.C.S. London: Edward Arnold. 1912. Demy 8vo. Pp. $\mathrm{xi}+308$.

1. In this Journal for November, 1911, the first edition of Dr. Armstrong's important monograph was somewhat fully noticed, and it is a matter for congratulation that a second edition has been so soon called for. The principal changes in the new edition are these :-

Chapter I., on the nature of glucose, has been considerably modified and expanded, and the rarer carbohydrates are more fully noticed, especially in their relation to enzymes. The chapter on the glucosides has been materially enlarged, and a new chapter dealing with the significance of the carbohydrates in plant physiology has been added. These problems are, as the author remarks, among the most fascinating of those now under investigation, and their study must surely widen our conceptions of vital change. 
A long outstanding puzzle is the chemical nature of the tannins, which are usually regarded as glucosides. Fischer and Freudenberg have now furnished almost complete proof that tannin is an acyl-derivative of glucose, with the high molecular weight of 1,700 , and they have succeeded in producing a synthetic compound from glucose which has all the properties of the tannins.

2. MoRE work has perhaps been done upon the digestion and assimilation of proteins than upon any of the other branches of metabolism, and in the present monograph Dr. Cathcart discusses the more important results published during the last decade, and their bearing upon the work of the earlier investigators.

The contents are distributed under nine chapters-viz., digestion and absorption of proteins; protein regeneration; feeding experiments with abiuret products of digestion; desaminisation; influence of the food on the composition of the tissues; protein requirements ; theories of protein metabolism; starvation; and work.

The problem of the metabolism of protein is one of the most complex and obscure in physiology, and it is somewhat discouraging to read that Carl Voit, after forty years of strenuous work in this field, could only come to the lame conclusion that " the unknown causes of metabolism are found in the cells of the organism." A cynic might well say: What a small mouse the mountain has brought forth.

Despite this scanty knowledge, physiologists still persist in the arduous quest, and Dr. Cathcart's monograph sums up concisely and clearly the results of a vast number of laborious investigations.

A fundamental question is that of the minimum amount of protein required daily by the body, and this is a matter not merely of scientific, but also of economic, importance.

Suffice it here to say that Chittenden's interesting experiments which led him to conclude that most people take far too much protein food, and that they would do better and live more healthily on a much smaller quantum 
have been trenchantly criticised, and cannot be considered as having been incontestably established. They are more fully referred to in the next review.

3. THIs book is an important contribution to a subject of fundamental import-viz., the amount of protein food required for nutrition.

The author is Professor of Physiology, Medical College, Calcutta, and he has fully utilised in his investigations the splendid opportunities afforded by a critical study of the prison dietaries of India.

He adduces a powerful body of evidence which appears to prove that a high protein ratio is necessary in child life in order to evolve a virile and active race of men. His final conclusions are in opposition to the stinted diet advocated by Chittenden, and $\mathrm{M}^{\prime} \mathrm{Cay}$ 's meritorious work deserves, and doubtless will receive, the closest attention from all who have to deal with dietaries for the young in schools and institutions.

The literary style of the book is attractive, and Dr. $M$ 'Cay manages to instil life into the dry bones of statistics and food tables, and his sane and temperate conclusions inspire confidence.

The author takes a broad view of the problems of nutrition, and shows himself to be thoroughly conversant with the enormous and scattered literature of the subject.

A pleasing feature of the book is the selection of excellent photographs of various types of the natives of India, illustrating the physique of the different tribes and races investigated.

It is interesting to note that in his earlier days $\mathrm{M}^{\circ}$ Cay was a believer in the validity of Chittenden's brilliant work. He recognises that Chittenden was the first to show that man ean live and do a certain amount of work upon an intake of protein much below the ordinary accepted standards without increasing-indeed with a considerable diminution of - the fuel value of the diet. It was not until evidence that appears absolutely convincing had been accumulated that M'Cay unwillingly 
resigned his belief in Chittenden's deductions, and has become a firm believer in a doctrine diametrically opposed to these.

We heartily commend this book to the serious attention of our readers, and will conclude our notice of it by a quotation which summarises Dr. M'Cay's views upon tropical dietary (p. 206) :

"We may conclude this study of the effects of the level of protein metabolism on the physique and general efficiency of different tropical tribes and races by stating that the facts afford ample proof of the all-important influence exerted by food, and particularly protein, in determining the degree of muscular development, the general physical endowment, the powers of endurance, resistance to disease, and, most important of all, the place a tribe or race has won for itself in manliness, courage, and soldierly instincts. We have no hesitation in saying that, among the tribes and races contrasted, the higher the level of protein interchange the more robust and energetic and the more manly the race."

4. Dr. Dakin has done much original work in the investigation of the processes of oxidation in the animal body, and is, therefore, well equipped to write such a summary as that under review.

The book aims to give an account of the principal chemical reactions involving oxidation or reduction which are known to take place in animal organisms, and it cannot be overlooked by those who are interested in the problems of metabolism.

Our views as to the graduated processes of oxidation were, up to a few years, very limited in scope. But Dr. Dakin points out that the bald statements that fats and sugars are oxidised in the body to carbon dioxide and water, while proteins yield urea in addition, are no longer considered all-sufficient explanations of the chemical rôle of these substances in the animal economy.

It is very important to observe that many of the striking biochemical oxidations of the living cell may be 
imitated more or less satisfactorily by experiments in vitro, and there is no evidence that suggests that the oxidative processes of the living organism differ in any fundamental way from chemical oxidations known to take place in inanimate nature.

The greater part of the book is devoted to the problems connected with oxidation of organic acids, and Chapter IV., on the carbohydrates, shows how meagre is our knowledge of the intermediate products of metabolism in this physiologically important class of substances.

The one definite statement that emerges from the discussion of carbohydrates is simply this (p. 85) :- " Lactic acid must therefore be regarded as one of the most important substances concerned with the intermediate metabolism of the carbohydrates. Unfortunately, we know nothing definite about the intermediate steps of the conversion in the animal body of glucose into lactic acid."

5. The joint authors of this book hold the D.P.H. Cantab., and they severally occupy positions, administrative and experimental, which yield them ample opportunities for an intimate knowledge of the industrial uses of lead, and of the preventive measures to be adopted against lead poisoning.

Hence the book is certain to be a valuable help to certifying factory surgeons, to medical officers of works concerned in any way with lead compounds, and, indeed, it should be welcomed by all medical men who take an intelligent interest in proceedings under the Workmen's Compensation Act.

The subject is very fully discussed under the headings, chiefly, of ætiology, susceptibility, pathology, diagnosis, chemistry, preventive measures, and the various processes employed in different trades.

Upon all these points a large mass of valuable information is supplied, and it is needless to go into details.

Where there is so much that is good and useful in the book it is a pity that it is marred by some blemishes which 
could easily have been avoided and which ought not to have been made.

We refer especially to slipshod English, and to inaccurate, nay, absurd chemical statements.

For example, p. 3 :-

"Chemically speaking, lead is a tetrad, and forms a number of organic derivatives, especially through the intervention of a particular oxide, minium. Lead forms metallic alkalies and alkaline earths (sic!) resembling silver in this direction, and also metallic compounds with zinc and copper; in this point it is very similar to silver."

What on earth is the meaning of this extraordinary sentence, which would serve as a test for parsing to be set before school children? In nearly all the important plumbic compounds lead functions as a dyad.

Again (p. 3) :-

"A number of oxides of the metal are known: two varieties of protoxides (mascicot (sic!) and litharge, protoxide hydrate and bioxide."

Compare this muddle with the concise statement in Newth's "Inorganic Chemistry," 10th Edition, p. 647 :-

"Five oxides of lead are known, having the composition $\mathrm{Pb}_{2} \mathrm{O}, \mathrm{PbO}, \mathrm{Pb}_{2} \mathrm{O}_{3} . \mathrm{Pb}_{3} \mathrm{O}_{4}, \mathrm{PbO}_{2}$."

Or, again (p. 4) :-

"In dilute solutions this sulphide is, however, appreciably soluble in mineral acids, and may introduce errors in analysis, especially as the solubility is distinctly increased by the presence of certain earthy salts" (sic!).

Once more (p. 5) :-

"It is possible to determine the presence of lead in a large volume without evaporating down the whole bulk of fluid. By this means liquid containing lead is treated with sulphide of copper, sulphide of mercury, or baryta water."

Neither the reviewer nor some of his expert chemical friends can make head or tail of this statement, and we need not give further examples of laxity of thought or carelessness of language. 
The book is likely to command a ready sale, and these minor defects can readily be corrected in the next edition.

In addition to figures illustrative of industrial processes, and of preventive measures concerned with lead, there are four excellent full-page plates, three of which are microphotographs of pathological changes in the animal tissues induced by lead.

The chief point brought out in the histological examination of the various organs is the occurrence of minute capillary hæmorrhages-e.g., in the intestine, lung, kidney, and nervous tissues. This phenomenon is not peculiar to lead poisoning, but has also been observed in connection with other heavy metals-e.g., $\mathrm{Bi}, \mathrm{Hg}$, Fe, and $\mathrm{Ni}$.

Immunity, Methods of Diagnosis and Therapy and their Practical Application. By Dr. Julius Citron, Assistant at the University Clinic of Berlin. Translated and Edited by A. L. GarBAT, M.D., Assistant Pathologist, German Hospital, N. Y. Philadelphia: P. Blakeston's Son \& Co. 1912. Royal 8vo. Pp. xiii. +208.

THIs little book has an attractive title, and covers in its 208 pages an enormous amount of ground. Beginning with definitions of immunity and antibody, and the law of specificity, Dr. Citron takes the reader through the various methods based upon these hypotheses, and used in the Berlin Clinic for diagnostic, therapeutic, and prophylactic purposes.

There are, moreover, included " certain fundamental considerations of questions on immunity which for the present are only of theoretical interest, but which owing to the rapid development of the subject may soon become of practical importance."

As the Editor points out, this work is not intended as a text-book, but as a practical handbook, and will have its greatest interest for those actually engaged in this branch of research.

The principles underlying Dr. Citron's work are admir- 
able. His insistance on the necessity for "controls" at every step is thoroughly sound, and he has some commendable observations on the "one job" specialist.

The chapters on Aggressins, on the History and Development of Tuberculins, and on the Cytolysins are of peculiar interest. The author is a cautious advocate of tuberculin given subcutaneously as a diagnostic in selected cases, and employs large and increasing doses for treatment.

In the chapters on cytolysins and "Complement Fixation" he is at his best. This part of the subject he studied with Wassermann himself, and he gives one a new idea of the wide application and exquisite delicacy of this method of investigation. It is characteristic of the race that the purity of the ingredients in the national food should be established day by day by a "Wassermann reaction."

It is, however, just in these chapters that the defects of the work are most apparent. The book has clearly suffered by translation, and so even when the meaning is not altogether lost in unintelligible English, it is too often obscured by mere verbosity.

We are gradually becoming accustomed to American spelling, but the advantage of the word "hemoptysis" over the more usual form is not obvious.

It is irritating, too, to find, after wading through a page of figures illustrative of some experiment, that the substance in question has been standardised in millegrammes, but administered in cc.s.

The idea of the book is good, but it attempts too much, and would be improved by being largely rewritten. It is clearly printed, well illustrated, and has a good index.

Manual of Medicine. By A. D. Woodwark, M.D., M.R.C.P. Edinburgh, Glasgow and London: Henry Frowde and Hodder \& Stoughton. 1912. Cr. 8vo. Pp. xi +409 .

ThIs work is another of the small text-books on medicine that are now so plentiful. Like the majority of these, its 
excuse for existence is that of "supplying a vade-mecum for the student clerking in the wards and a convenient reference for the busy practitioner."

Dr. Woodwark's book is no better and no worse than the greater number of these colourless manuals. Its information is accurate and generally well selected, but there is a rather confusing system of tabulation and subtabulation, that renders it hard for the "busy practitioner" of the preface to put his hurried finger on the spot he seeks.

The author advances two claims to originality. One is that the articles on infective fevers are arranged in alphabetical order-a point which seems to us of not much importance one way or the other, as the index has to be used to find out where the whole section on fevers is.

The second is a chapter on insanity, which is sound and useful, and certainly worth its place in the book.

The book would be very useful if there were not a dozen others like it; as it is, there seems to be no very definite reason for its production.

The Treatment of Infantile Paralysis. By Oskar Valpius, M.D. ; Professor Extraordinary at the University of Heidelburg. Translated by Alan H. TodD, M.B., B.S., B.Sc. (Lond.) ; House Surgeon, Guy's Hospital ; late Resident Surgical Officer, Royal National Orthopædic Hospital. With Introduction by J. JaCkson ClaRke, M.B. (Lond.), F.R.C.S. London : Baillière, Tindall \& Cox. 1912. Royal 8vo. Pp. $\mathrm{x}+318$.

"The Treatment of Infantile Paralysis" is an excellent English version of Oskar Valpius's valuable monograph by Alan H. Todd, who himself has had experience of orthopædic work.

The work is conveniently divided into two parts, preceded by some thirty pages of introduction.

The Introduction deals with the symptomology and course of anterior poliomyelitis, its ætiology and pathological anatomy. Lucid and very instructive, it contains 
the deductions to be drawn from the histories of a number of epidemics, which occurred mostly on the Continent.

Part I. discusses the general treatment of paralysis, both in the early and late stages. The chapter on orthopædic apparatus enters into sufficient technical details to enable the reader to grasp the principles of the appliances, and the uses of their various parts. In the section on "The Surgery of Paralysis," the writer goes very fully, and with the knowledge and acumen gained by his large experience, into- $(a)$ the treatment of paralytic contractions and deformities, and $(b)$ the means which are employed for restoration of function. Under $(a)$ Wrenching, Tendon Lengthening, and Tenotomy are considered; while (b) deals in an exhaustive yet concise manner with the methods, indications and results to be expected from Muscle Transplantation, Arthrodesis, Tendon Shortening and Tendon Transplantation, and Nerve Transplantation. In connection with the last the Professor introduces Dr. Stoffel's recent work on the internal anatomy of the nerve trunks, notably of the median nerve. The appreciation of Dr. Stoffel's researches raises nerve-grafting from a rather empirical to a more scientific and accurate procedure, by which greater success is ensured. The author's advice on the choice of methods is sound and in accordance with the views of most surgeons, who have to consider not only the time element, but also the expense and special after-treatment each case requires.

Part II., "Special," deals systematically with the paralysis of the various regions. It is remarkable for its wealth of clinical observation vividly recorded, both in the text and by the illustrations, which are numerous and carefully selected. Valpius devotes most space to the surgery of the shoulder-joint, as the literature on this subject is somewhat scanty. He reports twelve of his own cases in which he performed arthrodesis, and four where nerve transplantation was the treatment. His results for the most part were very satisfactory. The notes of his patients, and those recorded by other authorities, which we find throughout Part II., form a valuable 
asset of the work, especially when supplemented by the practical and useful information which the author, with his discriminating judgement, knows so well how to impart.

In conclusion, Professor Valpius's work will appeal to the medical profession in general, and to the orthopædic surgeon in particular, as an up-to-date, thorough, and yet succinct treatise on the treatment of infantile paralysis, and we are indebted to Dr. Todd for his excellent translation.

\section{RECENT WORKS ON SURGERY.}

1. Deformities, including Diseases of the Bones and Joints. A Text-book of Orthopædic Surgery. By A. H. TuBby; M.S. Lond., F.R.C.S. Eng. ; Surgeon to, and in charge of, the Orthopædic Department, Westminster Hospital, and Lecturer on Clinical and Orthopædic Surgery in the Medical School ; Surgeon to the Royal National Orthopædic Hospital; Consulting Surgeon to the Evelina Hospital for Sick Children, to Christ's Hospital and to the Seven Oaks Hospital for Hip Disease ; Corresponding Member, American Orthopædic Association. Second Edition. Illustrated by 70 Plates and over 1,000 Figures, of which nearly 400 are original, and by Notes of 54 Cases. In two volumes. Macmillan \& Co., Ltd. 1912.

2. A Manual of Surgical Treatment. By Sir W. WAtson Cheyne, Bart., C.B., D.Sc., LL.D., F.R.C.S., F.R.S., Hon. Surgeon-in-Ordinary to H. M. The King, Senior Surgeon to King's College Hospital; and F. F. Burghard, M.S. (Lond.), F.R.C.S., Surgeon to King's College Hospital and Senior Surgeon to the Children's Hospital, Paddington Green. New Edition. Entirely revised and largely rewritten with the assistance of T. P. Legr, M.S. (Lond.), F.R.C.S., Surgeon to the Royal Free Hospital, Assistant Surgeon to King's College Hospital ; and Arthur Edmunds, M.S. (Lond.), F.R.C.S., Surgeon to the Great Northern Central 
Hospital, Surgeon to Out-Patients the Children's Hospital, Paddington Green. In five volumes. Vols. II. and III. Longmans, Green \& Co. 1912. Royal 8vo.

3. A System of Surgery. Edited by C. C. Chоусе, B.Sc., M.D., F.R.C.S. ; Dean of, and Teacher of Operative Surgery in, the London School of Clinical Medicine (Post-Graduate); Surgeon to the Seamen's Hospital, Greenwich; Surgeon to Out-Patients at the Great Northern Central Hospital. Pathological Editor-J. Martin Beattie, M.A., M.D., C.M.; Professor of Bacteriology in the University of Liverpool and Bacteriologist to the City of Liverpool ; formerly Professor of Pathology and Bacteriology, and Dean of the Faculty of Medicine, in the University of Sheffield ; Honorary Pathologist to the Sheffield Royal Infirmary and Royal Hospital. In three volumes. Vol. II., with 18 Coloured Plates, 8 Black and White Plates and 375 Illustrations in the text. Cassell \& Co., Ltd. 1912. Pp. xii +1105 .

1. IN the sixteen years which have elapsed since the publication of the first edition of this work much has been added to our knowledge of this subject, and in the volumes before us the author has rightly included diseases of the bones and joints.

Volume I. is divided into sections, the first of which consists of some 300 pages devoted to a consideration of deformities of congenital origin. These include congenital deformities of the trunk, torticollis, congenital deformities of the limbs, congenital dislocations of the lower jaw and upper and lower extremities. Chapters five and six consist of over 80 pages, and are devoted to congenital dislocation of the hip. The last three chapters of this section are devoted to a consideration of club-foot.

In section II. of this volume will be found a description of non-congenital affections of the wrist and hand, some acquired affections of the legs and feet, and the various forms of acquired club-foot.

In section III. are included no less than sixteen chapters 
on "static deformities," while the last section (IV.) is devoted to affections of muscles. tendons, bursæ and fasciæ.

Volume II., almost similar in size, consists of six sections, in which are described such conditions as tuberculous disease of bones and joints, infective diseases of bones and joints, rickets and its deformities, arthritis and spondilitis deformans, other affections of bones and joints and paralytic deformities.

Four appendices complete this volume, in the first of which will be found an abstract of the final report of the Béraneck's Royal Commission on 'Tuberculosis, in the second tuberculin and its methods of application, in the third a description of a new apparatus for the treatment of spinal tuberculosis and the treatment of tuberculous abscess of bony origin by aspiration and injection. In Appendix IV. Förster's operation for spastic paralysis is described.

The two volumes before us form the most complete and authoritative work on this subject in the English language. This edition is really a new work. The illustrations are numerous and well reproduced. Each section has a most complete bibliography and the volumes are well indexed. The work is one which no general or orthopædic surgeon can afford to be without. We heartily congratulate the author upon the production of a work which is a credit to British surgery.

2. Volume II. of Sir Watson Cheyne's well-known manual consists of almost 600 pages and corresponds with the greater part of Volume II. and all Volume III. of the first edition. Like the first volume of this new edition the subject-matter has received eareful revision and in places has been largely rewritten. In the section devoted to the surgery of blood-vessels the principles of arteriorrhaphy are described and illustrated, and the application of this principle of arterial suture to the treatment of aneurysm, as introduced by Matas, is fully detailed. The treatment of fractures, both simple and compound, is practical and brought well up to date. The advice upon $x$-ray photography, and more especially by the stereoscopic method, 
as an aid to deciding upon whether the treatment should be operative or non-operative is sound.

Volume III. is about similar in size to Volume II., and corresponds to Volume IV. and almost half of Volume V. of the former edition. Every chapter exhibits the same evidences of careful revision as the first and second volumes. The surgery of the joints represents well over one-third of the book and leaves nothing to be desired. The surgery of the spine is very concise and might perhaps with advantage have been amplified. The surgical affections of the head and face are more fully described and well illustrated-many of the illustrations being new.

We can cordially and confidently recommend this new edition to every surgeon as an authoritative and reliable practical work.

3. Thrs volume opens with a magnificant monograph from the pen of Mr. W. Sampson Handley on the breast. Mr. Handley's work in connection with the spread of breast cancer by lymphatic permeation is so well-known that it is unnecessary for us to say more of the manner in which he has treated this subject than that it is quite up to the standard his previous work has led us to expect. The chapters on the face, lips and palate, and on the tongue are excellent. The section devoted to the stomach and duodenum, by Mr. James Sherrin, is very sound and practical as far as it goes. Other good sections are those on the intestines, by Mr. Alexander Miles; the appendix, by Mr. Percy Sargent, who is also responsible for the peritoneum ; hernia, by Mr. Laurie M'Gavin, who seems very partial to the use of filigree for the performance of radical cures. The section on the rectum and anal canal is written by Mr. H. S. Clogg, while that on the liver, gall-bladder, bile ducts and pancreas is by Mr. E. Guy Turner. Both sections are concise and practical.

Of the remaining chapters that devoted to a consideration of the upper and lower urinary tract, by Mr. Thomson Walker, is by far the most extensive.

The volume well maintains the high standard set by the 
first volume though, as is to be expected in a work of this sort, a certain amount of inequality in the merit of the various sections must exist. The work is one we can confidently recommend. The illustrations are abundant, well selected and very nicely reproduced. They add much to the value of the letterpress.

A Treatise on Treatment. Designed for the use of Practitioners and Students of Medicine. By Jogender LAL Chundra, L.M.S. (Calcutta University), Rustomjee Scholar; M.B. Calcutta University, with First Place; late Lecturer on Anatomy, College of Physicians and Surgeons, Calcutta ; late Medical Officer, Corporation of Calcutta; Examiner in Clinical Medicine, Nationa Medical College, Calcutta. With Charts and Illustrations. First Edition. Calcutta: 5, Gopee Kristo Paul's Lane. 1911. Pp. 684.

WE congratulate Dr. J. L. Chundra on his research, for he has levied contributions from the medical journals of all countries, and produced a useful Vade mecum for medical practitioners. The book is primarily intended for practitioners living in India, but as much of the matter is valuable, all may benefit by consulting it. There is no claim made for originality, therefore there is little left for us to notice other than the admirable arrangement of the contents and the industry of the compiler in the field of therapeutics.

A Manual of Elementary Zoology. By L. A. Borrodalle, M.A. London : Henry Frowde, Hodder \& Stoughton. 1912. Crown 8vo. Pp. x. +470.

THIs is an excellent manual of Zoology. The types selected are those of most general interest to students, and their treatment is illuminating, each type standing out clear and complete.

Connecting chapters on general structure and function form links which give coherence to the series of studies. 
The most recent discoveries have been incorporated, and the volume is both reliable and up to date.

The author evidently approves the contrast drawn by Dobell between the protozoa as non-cellular and the metazoa as cellular, holding that a cell is a portion of the body of a whole organism which has become specialised for the performance of particular functions, and not a whole organism with possibly some functions developed and others suppressed. To most workers the suggestion will be confusing rather than illuminating.

There is a large number of illustrations (301). Some, like the poor, we have always with us, but the great majority are original, and reflect credit both on author and artists.

"Minor Surgery." By Leonard A. Bidweld, F.R.C.S., Senior Surgeon to West London Hospital, \&c. Second Edition, revised and enlarged. One hundred and twenty-nine Illustrations. London: University of London Press ; Hodder \& Stoughton and Henry Frowde. 1913. Demy 8vo. Pp. xvi +299.

Perhaps the best review of this work is contained in the publisher's preface to the second edition :-

"The fact that a second edition of this work has become necessary within twelve months of the publication of the first is sufficient indication that it met a need. Based, as it is, upon the practice and experience of a surgeon to a large hospital, it lays down definite and distinct lines of teaching which admit of no ambiguity," \&c.

To this we would like to add that the reader will not find any novelty or indeed any line of treatment which has not stood the test of time. From a student's point of view this is as it should be, but surgeons will be disappointed in that the author has not crystallised any ideas from his vast experience, which although not in accordance with the teaching of the average text-book, yet are more worth recording than that explaining the methods of applying a capelin bandage. 
Transactions of the American Otological Scciety. 209

Transactions of the American Otological Society. Vol. XII. Part III. New Bedford, Massachusetts. 1912. Pp. xii +218 .

Aт the Forty-fifth Annual Meeting of the American Otological Society, Dr. J. H. Bryan related several cases of great interest in which affections of the posterior sinuses of the nose produced violent reflex pain in the ear. He observed :- "Cases in which earache is a symptom of posterior sinus diseases are undoubtedly rare, but they, according to my experience, occur sufficiently often to make a record of them desirable. The pain is simply reflex in character, and does not depend upon any pathological condition present in the ear. In the several cases of this reflex pain that have come under my observation, I have found nothing more than a very moderate form of chronic catarrhal inflammation in the ear, and even that has only been present in two of my cases."

A series of papers was then read on Labyrinthine Affections, and many interesting remarks were made and instructive cases were mentioned.

Dr. J. B. Rae discussed the course of Acute Diffuse Suppuration of the Labyrinth, and clearly differentiated between a circumscribed and a diffuse inflammation. He also stated that many of these cases rapidly get better without operation, and that, on the whole, the wisest course of action is either to leave them alone, or to do the major labyrinthine operation; that the half-way house of a "Radical Mastoid" alone is not a wise proceeding. He lays down that the special points to be observed in an acute invasion of the labyrinth are as follow :-

(1) Under general conditions, the presence of temperature and headache: headache not to be confused with pain in the ear or temporal region.

(2) Under local conditions it is important to observe whether it is an acute or a chronic ear affection, and especially the presence of a marginal perforation in the upper posterior part of the drum. 
(3) The spontaneous evidences are (a) vertigo, with nausea and vomiting; $(b)$ spontaneous rotatory nystagmus, and (c) disturbances of equilibrium.

Under this heading, note that the spontaneous nystagmus is to the diseased side for the first forty-eight hours or so, and at the end of that time may have entirely disappeared, or be evident only on extreme abduction. As the disease progresses, more destruction takes place, and as a result of the imbalance of the tonus of the centres on the two sides a spontaneous rotatory nystagmus will now be to the good side, and again, after a short period the equilibrium will be established, and this spontaneous nystagmus will rapidly decrease. Note, therefore, that the whole of this "symptom complex" may occur" and subside in a period of four or five days. Should the case progress to further complications, they will be either meningeal or take the form of an abscess in the corebellum. The first may be considered invariably fatal, and the latter within the bounds of cure. Here lumbar puncture will be of great assistance. When cerebellar abscess is present there may be persistent. spontaneous rotatory nystagmus. Unlike that of vestibular origin the nystagmus remains to the affected side and increases in intensity from day to day.

Dr. N. H. Pierce related three cases in which surgical interference met with success, and the labyrinthine affection rapidly subsided. He laid great stress on the fact that it may be impossible to differentiate between an acute serous and a purulent labyrinthitis.

Dr. Shambaugh contributed an article on the origin of Compensatory Tonus after. Destruction of the Labyrinth. He concluded his paper with the following remarks :- "The restoration of equilibrium which follows the destruction of both labyrinths is never a complete restoration of the normal equilibrium. The extra labyrinth tonus which supplants the labyrinth tonus is not as perfect a mechanism for preserving the equilibrium as is the tonus from the highly specialised sense organs in the labyrinth. In the case of the sudden loss of one labyrinth 
the rapid re-adjustment of equilibrium which follows is dependent, as pointed out above, on the development of the extra labyrinth compensatory tonus. The re-adjustment is not a complete substitute for the labyrinth tonus. It is only in cases of long standing unilateral labyrinth destruction where the restoration of equilibrium is apparently perfect, and here the compensatory tonus from the opposite labyrinth has fully developed so as to supplant completely the compensatory extra labyrinth tonus."

In a very interesting paper on the Insidious Latent Period of. Streptococcus mucosus, Dr. F. Whiting mentioned several cases which show that even after one has operated on ears and considered them to be quite out of danger and practically healed, a sudden re-appearance of symptoms going on to meningitis and death may occur, and this without their being any obvious cause for it, and by bacterial examination he has found in these cases that this particular streptococcus is always present. It behoves one, therefore, in cases where this organism is found, to give special care to the prognosis.

\section{EDMONTON MEDICAL SOCIETY.}

WE are informed that this Society has established a Library. The librarian, Mr. Heber C. Jamieson, M.B., will be very glarl to receive gratuitous literature. His address is 501 Tegler Block, Edmonton, Alberta, Canada. We visited this capital of the Province of Alberta in the year 1909, and since that date the growth of the city, which is in the same latitude at Manchester, has been phenomenal. The estimated population in July, 1912, was 53,383. According to the Census of 1911 it was not half that figuro-namely, 24,882. 